\title{
X-RAY DIFFRACTION AND VIBRATIONAL SPECTROSCOPIC STUDIES OF THE INTERMOLECULAR INTERACTIONS ON THE GRINDING AND COMPACTION BEHAVIOURS OF LOPINAVIR AND RITONAVIR CRYSTALS
}

\author{
ARIF BUDI SETIANTO ${ }^{1,2 *}$, YUDA PRASETYA NUGRAHA ${ }^{2,5}$, VEINARDI SUENDO ${ }^{3}$, \\ AHMAD AINUROFIQ ${ }^{4}$, HIDEHIRO UEKUSA $^{5}$ and SUNDANI NURONO SOEWANDHI ${ }^{2}$ \\ 'Department of Pharmaceutics and Pharmaceutical Technology, Faculty of Pharmacy, \\ Universitas Ahmad Dahlan, Indonesia \\ ${ }^{2}$ Pharmaceutics Research Groups, School of Pharmacy, Institut Teknologi Bandung, Indonesia \\ ${ }^{3}$ Inorganic and Physical Chemistry Division, Faculty of Mathematics and Natural Sciences, \\ Institut Technology Bandung, Indonesia \\ ${ }^{4}$ Pharmaceutical Technology and Drug Delivery, Department of Pharmacy, \\ Universitas Sebelas Maret, Ir. Sutami 36A, Surakarta, Indonesia \\ ${ }^{5}$ Department of Chemistry and Materials Science, Graduate School of Science, \\ Tokyo Institute of Technology, 2-12-1, Okayama, Meguro, Tokyo 152-8551, Japan
}

\begin{abstract}
Lopinavir (LPV) and ritonavir (RTV) are anti-viral drugs used in combination and commonly prepared through hot-melt extrusion techniques. Mechanical processes are greatly involved, including blending and milling. Therefore, the crystal behavior of LPV and RTV under the mechanical process is an interesting study. Here, the LPV, RTV, and their mixtures were processed by two different treatments: grinding and compression processes. The solid-state properties of the drugs were evaluated by powder X-ray diffraction (PXRD) differential scanning calorimetry (DSC), Fourier transform infrared spectroscopy (FTIR), Raman spectroscopy. Single-crystal XRD analysis was also carried out to confirm the packing structure in the crystal lattice. It was observed that LPV was very sensitive to the grinding process, where it tends to form an amorphous solid in both the pure and mixture forms. On the other hand, RTV has a very stable crystalline structure and was able to retain its crystallinity even under grinding. Both LPV and RTV were observed to be quite stable under compression, where both retained their crystalline form with only slight changes in their $d$-spacing values. This study highlighted the molecular origin of LPV and RTV crystal behavior after grinding and compression processes.
\end{abstract}

Keywords: compression, crystal behavior, grinding, intermolecular interactions, lopinavir, ritonavir, vibrational spectroscopy

Grinding and compression are among the process steps used to prepare pharmaceutical ingredients. The objectives of this treatment include the reduction of particle size to improve the solubility or to make the compact solids to form tablets. Changes in the surface of the pharmaceutically active solid ingredient during particle size reduction and compression can cause a crystal lattice alteration resulting in changes in solubility, stability, and hygroscopicity (1-3). Grinding is a simple and common method of making amorphous crystalline solids used in the pharmaceutical industry to reduce the particle size to improve the solubility $(4,5)$. The grinding process involves several stages such as cutting, grinding and lacing on the surface of the drug particles. Energy is applied to induce the changes in the nature of the solids, e.g., from crystalline to amorphous forms and vice versa, or to form the polymorph (6-11). Before preparation of the tablets, the pharmaceutically active bulk powder is blended with various excipients and then compressed into a coherent mass. During the compression of a powder

* Corresponding author: e-mail: arif.setianto@pharm.uad.ac.id 
bed, the individual crystallites underwent rearrangement followed by the deformation or fracture. The precise nature of the deformation is determined by the molecular arrangement within the crystal lattice, the intermolecular interactions that impart rigidity to the lattice, the presence of defects or disorder, and the orientation of the lattice relative to the compressive stress tensors. To date, the relationship between the crystal lattice structure and the tableting properties of pharmaceutical solids was not adequately understood. It would certainly be useful to study the changes in the crystal lattice under compressive stresses. Powder X-ray diffraction (PXRD) was uniquely suited for this purpose $(12,13)$.

Compression is a series of processes during the preparation of the tablet dosage form. The energy involved in the process could change the solid phase or excipient drugs through solid-state mechanisms $(14,15)$.

Lopinavir (LPV) and ritonavir (RTV) are two active ingredients used as human immunodeficiency virus (HIV) protease inhibitors. The efficacy of the treatment by ritonavir alone was found to be unsatisfactory. Co-administered LPV and RTV were effective and at the same time, could reduce the total amount of the dose. Both compounds were among the Biopharmaceutical Classification System (BCS) class II; thus, they were poorly soluble in water, and LPV was also hygroscopic (16). The flexible chemical structure of LPV with four chiral atoms has the potential to bind to intramolecular hydrogen extensively. The flexibility of this structure also allows LPV to be more oriented to the coordinates of molecules in its energy landscape, making it possible to formulate it in amorphous or crystalline form (17). A previous study had reported an improvement in the solubility of the combination of LPV-RTV tablets made from the amorphous solids via hot-melt extrusion (HME), which eventually increased their bioavailability $(18,19)$. Currently, the HME technique was considered as a new technology to manufacture tablets to increase the solubility and bioavailability of the drugs. This technique aimed to form more soluble, amorphous drugs from the solid form via stages including grinding, mixing, melting, and compression $(20,21)$.

Tabletability, which is the ability of the powders to be made into a tablet, has often been associated with molecular-level crystalline structures. Other factors were the slip-plane system (22), the thermal stability properties (23), and the molecular density in polymorphs (24). The existence of the slip plane in the crystal lattice increases the plastic deformation of the powder material and affects the compressibility. Meanwhile, the molecular density affects the compactibility, which also supports tabletability $(1,2,25)$. The existence of the slip plane in the crystal lattice increased the plastic deformation of the powder material, thus greatly affected the compressibility; meanwhile, the molecular density affected the compactibility (2).

The changes in the phases of drug molecules due to manufacturing processes, such as grinding and compression, were analyzed using PXRD. The interactions between two or more drugs during the processes could also be identified and analyzed using PXRD by the presence of new diffraction interferences representing new phases $(26,27)$. These new phases and interactions appeared as different functional group vibrational modes in IR and Raman spectra $(28,29)$.

The current study aimed to analyze the changes in the crystal lattice of a mixture of LPV and RTV during the grinding and compression using PXRD as well as IR and Raman spectroscopies. The findings were then compared to the virgin (unstressed) powder. This paper also highlights the slip plan analysis of LPV and RTV compression based on single-crystal X-ray diffraction (SCXRD), FTIR, and Raman spectroscopy.

\section{Materials and methods \\ Materials}

Lopinavir and ritonavir were purchased from Hetero Labs, India (batch no. LN0010612 and R10050712, respectively). The initial characterization of these materials categorized that lopinavir existed in a higher hydrated form and ritonavir as crystalline form I. All chemicals in this research were used without any purification.

An LPV single-crystal data/file (CIF) from the experiment was collected at $93 \mathrm{~K}$ on a Rigaku R-AXIS RAPID II instrument with rotating anode $\mathrm{Cu}-\mathrm{K} \alpha$ radiation $(\lambda=1.541865 \AA)$ in $\omega$-scan mode. The initial crystal structure of LPV was solved by direct methods using SHELXS. RTV was cited from Bauer et al. (2001) (30). Single-crystal LPV and RTV illustrations were processed from Mercury 3.7 software.

\section{Grinding and compression}

About $2 \mathrm{~g}$ of each powder LPV, RTV and the equimolar mixture $(1: 1)$ of LPV and RTV (LPV/r) were ground by using a Retsch RM 200 mortar grinder (Retsch, Germany) at the scale of 4 for 5, 15, 30 and $60 \mathrm{~min}$. Different $400 \mathrm{mg}$ samples of each powder were compressed with a manual hydraulic press (Carver Instruments, NY, USA). The compaction bulk was prepared by using compression loads $37.5,75,112.5,150,187.5$, and 262.5 MPa for 
$1 \mathrm{~min}$ of dwell time with $1.3 \mathrm{~cm}$ diameter, flat-faced round punches. All processing and compaction of LPV and RTV powders were conducted in an environmentally controlled room at $25^{\circ} \mathrm{C}$ and $75 \% \mathrm{RH}$. After the compression, tablets were carefully ejected out of the die and stored in a closed desiccator for $24 \mathrm{~h}$ before any tensile strength measurement.

\section{Powder X-ray diffraction analysis}

PXRD patterns were collected in transmission mode using a Rigaku SmartLab system (Rigaku, Tokyo, Japan) with $\mathrm{Cu}-\mathrm{K} \alpha$ radiation generated at $45 \mathrm{kV}$ and $200 \mathrm{~mA}$. The sample was placed on a spectroscopic-grade thin polyester film (Mylar ${ }^{\circledR}$, Chemplex Industries, Inc., USA) and measured at room temperature. Data were recorded with a step size of $0.01^{\circ}$ and a scanning speed of $5^{\circ} \mathrm{min}^{-1}$.

\section{Differential scanning calorimetry (DSC) thermal analysis}

The thermal properties of powders were studied using DSC (Perkin Elmer, Waltham, Massachusetts, USA). The system was calibrated using indium and zinc. Approximately 5-10 mg samples were placed in a standard aluminum pan and sealed with a lid containing a pinhole. Samples were analyzed at a heating rate of $5^{\circ} \mathrm{C} \mathrm{min}^{-1}$ from 35 to $175^{\circ} \mathrm{C}$ under a dry nitrogen purge of $60 \mathrm{~mL} \cdot \mathrm{min}^{-1}$.

\section{Fourier transform infrared spectroscopy (FTIR) and Raman analysis.}

An attenuated total reflectance (ATR) FTIR study was performed on a Bruker Alpha-E FTIR spectrometer with a resolution of $4 \mathrm{~cm}^{-1}$, while Raman spectra were acquired using a Bruker Senterra Raman Microscope spectrometer. The microscope was equipped with an Olympus long working distance M-Plan semi-apochromatic objective lens (50x). The spectrometer was equipped with an Andor iDus DU420A CCD detector. During the measurement, the CCD detector was set into a deepcool mode at $-80^{\circ} \mathrm{C}$. The range of all measurements was $500-4000 \mathrm{~cm}^{-1}$. A diode laser was used as an excitation laser at a wavelength of $785 \mathrm{~nm}$.

\section{RESULT AND DISCUSSION}

\section{PXRD characterization}

Figure 1 shows the PXRD diffractograms for LPV, RTV, and its mixture, LPV/r, after various grinding times up to $60 \mathrm{~min}$. The LPV samples tended to become amorphous easily and were nearly completely amorphous only after 5 min of grinding (Fig. 1a). The LPV sample appeared as very broad and weak diffraction peaks indicating a low concentration of small crystallites that were still present in the samples. On the other hand, RTV samples appeared to retain their crystallinity longer (Fig. 1b). The RTV samples showed a slight decrease in both crystallinity and crystallite size after various grinding times. A slight decrease of crystallinity was observed via further quantitative analysis (Table 1) $(31,32)$. LPV/r samples also showed similar behaviors as LPV samples under grinding, where the LPV phase tends to be completely amorphous only after 5 min of grinding. In the same duration, the crystalline phase of RTV is still present in the mixture. The presence of LPV in the mixture is necessary to help the formation of the amorphous phase of RTV. The RTV diffraction peaks became weaker and broader when the material was ground for various times in the mixture, while the hump on the $2 \theta$ angle at $21^{\circ}$ is still stronger (Fig. 1c).

Compression or compaction is a different mechanical treatment than the grinding process. Here, we applied a certain static pressure to the drug samples without any impact, and the sample was allowed to relax. Thus, different responses were
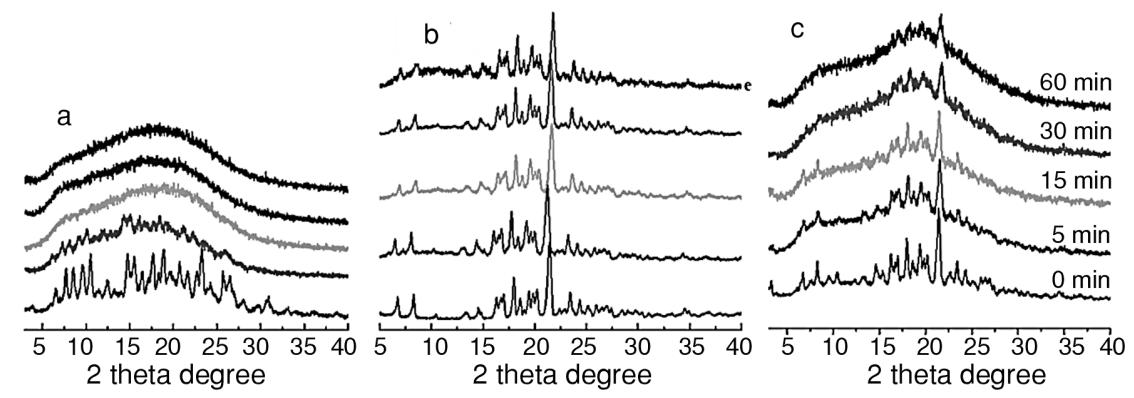

Figure 1. PXRD diffractogram pattern of (a) LPV, (b) RTV, and (c) LPV/r samples after grinding. 
hypothetically expected from the drug crystal behavior under compression pressure than under grinding pressure (33). Under compression, pure LPV showed different behavior than the ground samples: pure LPV preserved its crystalline form quite well up to $187.5 \mathrm{MPa}$. Here, the amorphous phase slightly increased but not significantly (Fig. 2a). The pure RTV retained its crystallinity even

Table 1. FWHM, Crystallite size, and crystallinity of LPV-RTV after grinding and compression.

\begin{tabular}{|c|c|c|c|}
\hline RTV grinded & FWHM (rad) & Crystallite size (nm) & Crystalinity (\%) \\
\hline $0 \min$ & $(5.1 \pm 1.3) \cdot 10^{-3}$ & $28.89 \pm 6.01$ & $70.99 \pm 2.38$ \\
\hline $5 \mathrm{~min}$ & $(5.2 \pm 1.7) \cdot 10^{-3}$ & $29.2 \pm 7.57$ & $63.90 \pm 2.81$ \\
\hline $15 \mathrm{~min}$ & $(6.2 \pm 1.4) \cdot 10^{-3}$ & $23.84 \pm 4.38$ & $47.78 \pm 2.64$ \\
\hline $30 \mathrm{~min}$ & $(5.9 \pm 1.3) \cdot 10^{-3}$ & $24.71 \pm 4.6$ & $49.54 \pm 2.55$ \\
\hline $60 \mathrm{~min}$ & $(6.5 \pm 0.8) \cdot 10^{-3}$ & $21.82 \pm 2.26$ & $42.52 \pm 0.45$ \\
\hline \multicolumn{4}{|l|}{ RTV compressed } \\
\hline $0 \mathrm{MPa}$ & $(5.1 \pm 1.3) \cdot 10^{-3}$ & $28.89 \pm 6.01$ & $70.99 \pm 2.38$ \\
\hline $37.5 \mathrm{MPa}$ & $(7.1 \pm 1.8) \cdot 10^{-3}$ & $20.93 \pm 4.47$ & $54.30 \pm 1.86$ \\
\hline $75 \mathrm{MPa}$ & $(6.8 \pm 1.5) \cdot 10^{-3}$ & $21.57 \pm 3.99$ & $52.94 \pm 0.87$ \\
\hline $187.5 \mathrm{MPa}$ & $(7.8 \pm 1.3) \cdot 10^{-3}$ & $18.28 \pm 2.58$ & $49.78 \pm 0.20$ \\
\hline \multicolumn{4}{|l|}{ LPV compressed } \\
\hline $0 \mathrm{MPa}$ & $(6 \pm 0.5) \cdot 10^{-3}$ & $23.46 \pm 2.01$ & $63.04 \pm 0.76$ \\
\hline $37.5 \mathrm{MPa}$ & $(8.3 \pm 1.1) \cdot 10^{-3}$ & $17.17 \pm 2.15$ & $23.28 \pm 1.56$ \\
\hline $75 \mathrm{MPa}$ & $(7.6 \pm 0.4) \cdot 10^{-3}$ & $18.46 \pm 1.02$ & $29.48 \pm 1.36$ \\
\hline $187.5 \mathrm{MPa}$ & $(7.8 \pm 1) \cdot 10^{-3}$ & $18.30 \pm 2.46$ & $34.67 \pm 0.56$ \\
\hline
\end{tabular}

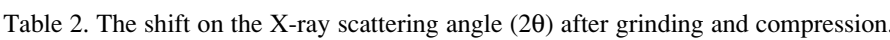

\begin{tabular}{|c|c|c|c|c|}
\hline Treatment & Variable & LPV & RTV & $\mathrm{LPV} / \mathrm{r}$ \\
\hline \multirow[t]{4}{*}{ Grinding } & $5 \mathrm{~min}$ & -3 & -2 & +1 \\
\hline & $15 \mathrm{~min}$ & amorphous & +2 & +1 \\
\hline & $30 \mathrm{~min}$ & amorphous & +1 & amorphous +3 \\
\hline & $60 \mathrm{~min}$ & amorphous & +3 & amorphous +3 \\
\hline \multirow[t]{3}{*}{ Compression } & $37.5 \mathrm{MPa}$ & +5 & +2 & +4 \\
\hline & $75 \mathrm{MPa}$ & +3 & +1 & +2 \\
\hline & $187.5 \mathrm{MPa}$ & +1 & +1 & +1 \\
\hline
\end{tabular}

(+) represents the shift to a larger angle, while (-) represents the shift to a smaller angle with respect to the virgin sample, respectively.
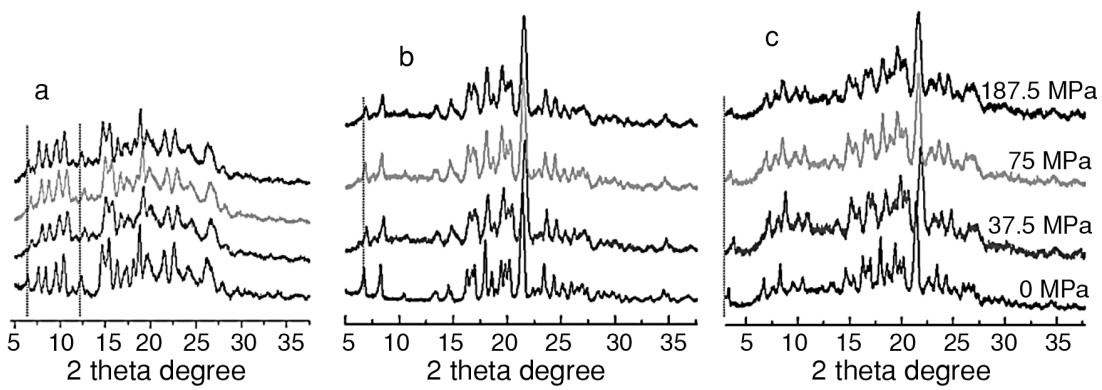

Figure 2. PXRD diffractogram pattern of compressed LPV (a), RTV (b), and LPV/r (c) samples. 

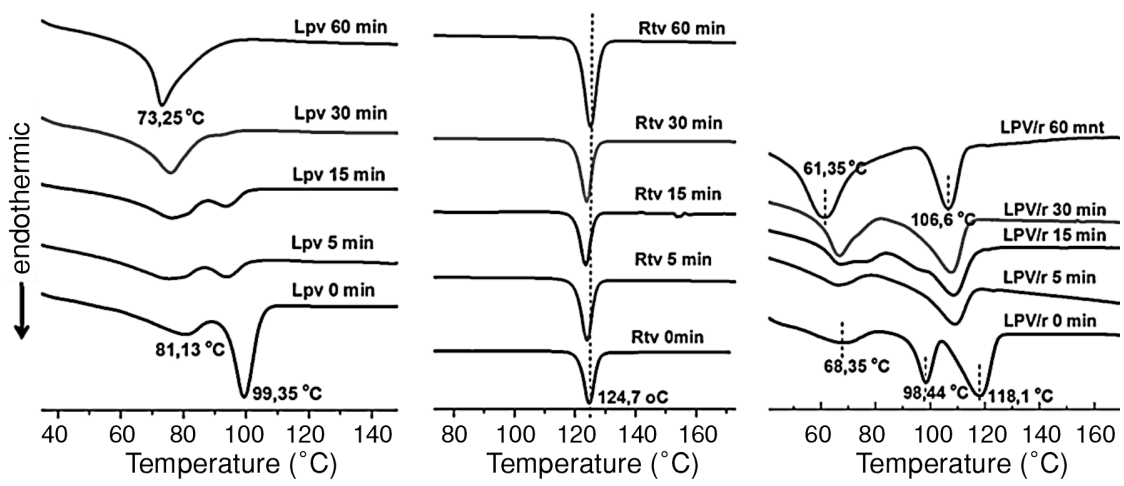

Figure 3. DSC thermograms of LPV, RTV, and LPV/r samples after grinding.
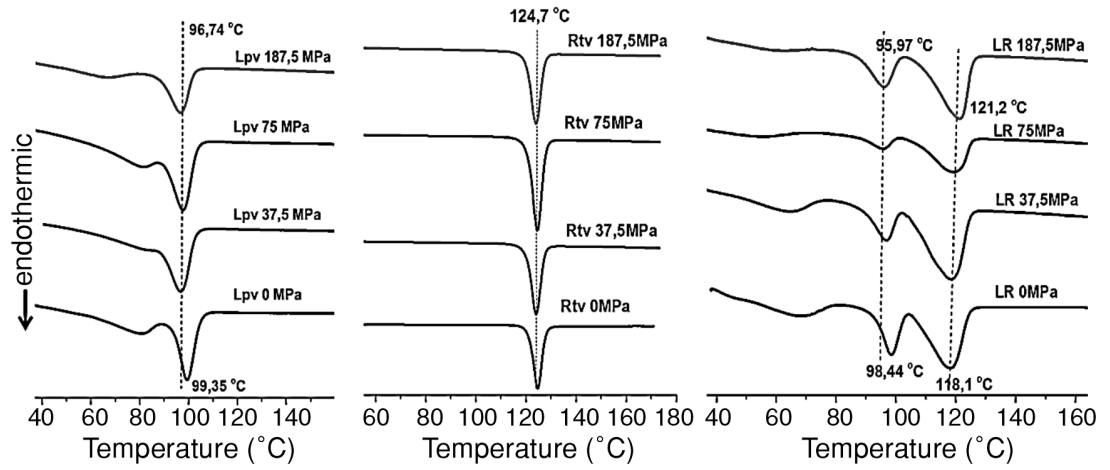

Figure 4. DSC thermograms of compressed LPV, RTV, and LPV/r samples.

better in the compaction process (Fig. 2b). The crystalline phase of LPV and RTV has not changed as a result of the compression process (Fig. 2c).

Another feature that resulted from the mechanical grinding and compression process was the shift in diffraction peaks. The shifting of those diffraction peaks is shown in Figures 1 and 2 and further tabulated in Table 2. Grinding at an interval of $5 \mathrm{~min}$ resulted in the increase of the space in the crystal lattice in both LPV and RTV, whereas the diffraction peaks at $2 \theta$ shifted to the left ( -3 and -2$)$. However, as the grinding time increased, the space in the RTV crystal lattice became smaller (shifted to the right, +2) while the space in LPV stayed shifted to the left and eventually became amorphous. The effect of the grinding process in the LPV/r mixture represented a total shift of both LPV and RTV. Furthermore, the compression caused the space in the crystal lattice of LPV, RTV, and the mixture LPV/r to become smaller. The compression at $37.5 \mathrm{MPa}$ significantly changed the space of the crystal lattice of the LPV (shifted to the right, +5 ), when compared to the greater compression force. The results showed that the LPV tended to shift and form a space in the crystal lattice more readily when the compression was applied, compared to the RTV.

\section{DSC characterization}

DSC thermal analysis was carried out for the characterization of crystal behavior before and after grinding and compression. The DSC thermogram (Fig. 3) displays the different patterns and intensity of subsequent dehydration $\left(80.8^{\circ} \mathrm{C}\right)$ and melting $\left(99.8^{\circ} \mathrm{C}\right)$ of the crystalline LPV, compared to the ground LPV. There was a decrease in the peak of the melting point of the ground LPV until the dehydration peak, either alone or in a mixture LPV/r $\left(73.25^{\circ} \mathrm{C}\right.$ for the dehydration peak of LPV and $106.8^{\circ} \mathrm{C}$ for the melting peak of RTV).

The crystal water is released from LPV in the azeotropic form with ethanol (34); if the only hydrate, it would be released at a temperature of $90-100^{\circ} \mathrm{C}$ in normal conditions. There was no endothermal peak observed on the LPV melting 
peak after grinding at $60 \mathrm{~min}$ when examined alone on in an LPV/r mixture, which was probably because the LPV has changed into its amorphous form. The endothermic peak of the RTV remains apparent, even though the RTV has undergone grinding and compression; thus, the RTV remained in crystalline form. Compression exposure with various pressures does not change the crystalline form in either LPV or RTV (Fig. 4).

\section{ATR-FTIR and Raman characterization}

Vibrational spectroscopy such as FTIR and Raman measurements was carried out to character- ize the material in solid-state and to gain insight into the interactions at the molecular level. At the molecular level, intermolecular interactions such as hydrogen bonds and van der Waals interactions were the key factor responsible for the behavior of molecular crystals such as LPV and RTV. Thus, it was possible to apply vibrational spectroscopy to probe the intermolecular interactions directly to reveal the origin of crystal behavior of solid-state properties. The RTV crystal showed strong peaks in the region of $3200 \mathrm{~cm}^{-1}$ to $3400 \mathrm{~cm}^{-1}$ (3357 $\mathrm{cm}^{-1}$, Figs. 5 and 6), which are attributed to $\mathrm{N}-\mathrm{H}$ stretching of a secondary amide. Strong peaks at $1716,1526 \mathrm{~cm}^{-1}$ and

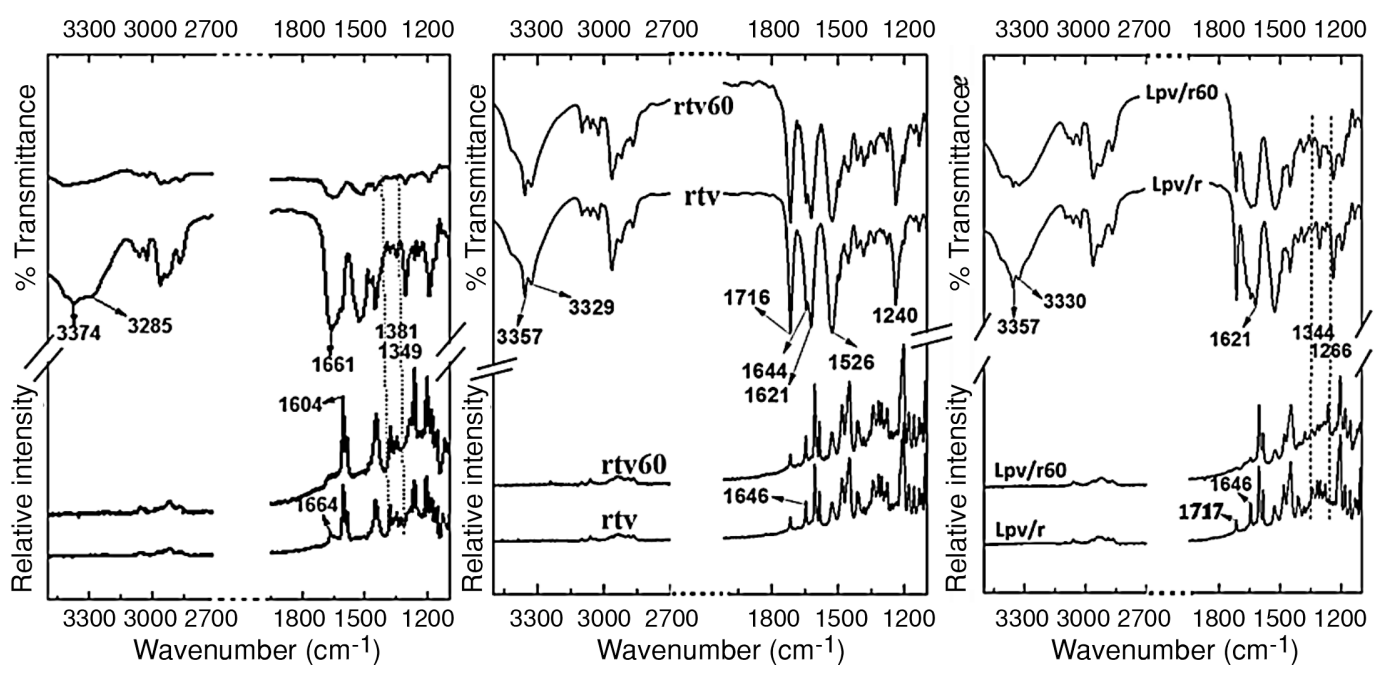

Figure 5. ATR-FTIR and Raman spectra of LPV, RTV, and LPV/r samples after grinding.
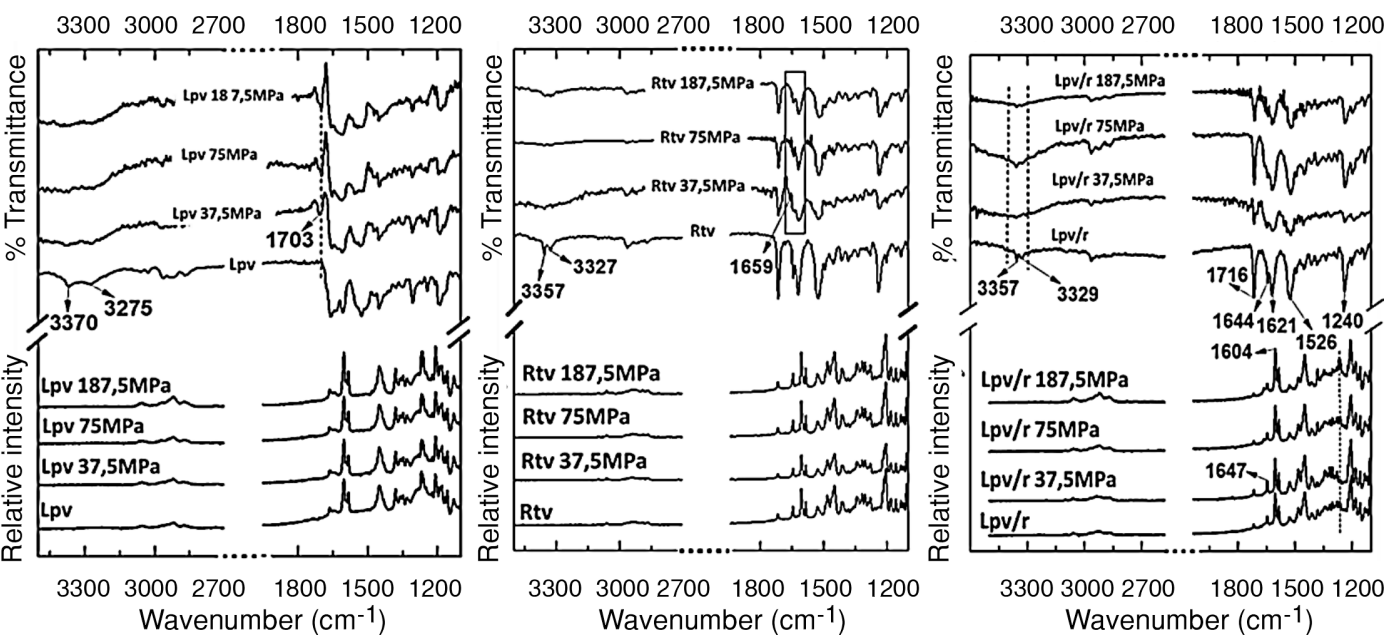

Figure 6. ATR-FTIR and Raman spectra of compressed LPV, RTV, and LPV/r samples. 


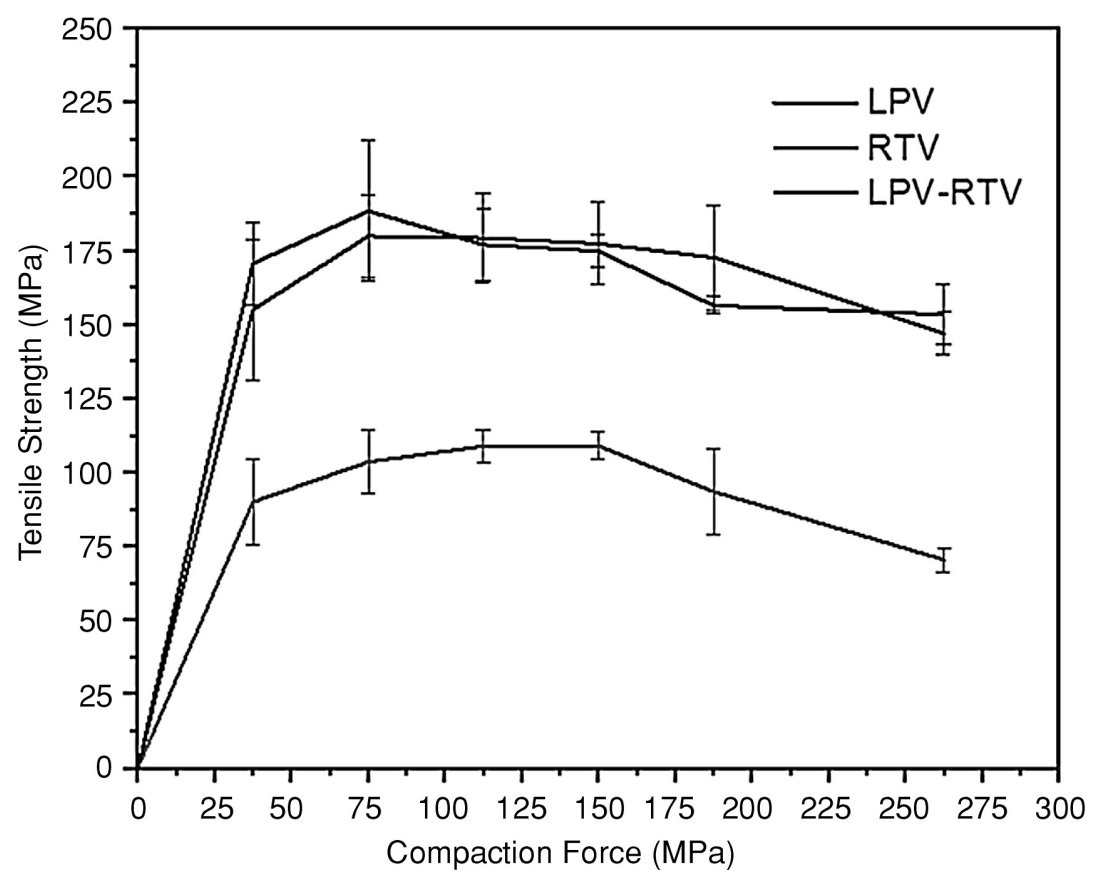

Figure 7. Plots of tensile strength as a function of compression force for LPV, RTV and LPV/r samples.

1717, $1527 \mathrm{~cm}^{-1}$ were observed (FTIR and Raman measurements, respectively), which can be assigned to carbonyl stretch $(\mathrm{C}=\mathrm{O})$ and the $\mathrm{N}-\mathrm{H}$ bending of a secondary amide. $\mathrm{C}-\mathrm{N}$ stretching was confirmed by the presence of a relatively sharp peak at $1238 \mathrm{~cm}^{-1}$ (35). The peaks of the infrared and Raman spectrum of the RTV do not shift the wavenumbers, and there is no weakening or amplification of the vibrations despite grinding and compression (Figs. 5 and 6). In the spectrum of LPV and RTV after 60 min grinding, a disappearance of the sharp peaks attributed to the $\mathrm{N}-\mathrm{H}$ stretching of the secondary amide was observed with the significant broadening of the region. Although no shift in the peaks is observed in the carbonyl (1600-1800 $\mathrm{cm}^{-1}$ ) group in FTIR and Raman measurements as well as in the fingerprint region, significant broadening of all peaks was observed. These observations are likely to show the interaction of hydrogen from the $-\mathrm{OH}$ group with a carbonyl group $(\mathrm{C}=\mathrm{O})$ of the amide linkage present in RTV, thus clearly indicating the possibility of intermolecular hydrogen bonding in amorphous LPV and RTV (36).

The amorphous nature of LPV due to grinding is also supported by FTIR and Raman data (Fig. 5). Spectra FTIR at the peak of wavenumbers 3375 , $3285,1661 \mathrm{~cm}^{-1}$, and in the area between 1381 to $1349 \mathrm{~cm}^{-1}$, show a sharp decrease in intensity. Vibrations at wavenumbers 3371, 3285, and 1661 $\mathrm{cm}^{-1}$ were successively derived from stretching of the $-\mathrm{OH},>\mathrm{NH}$, and bending groups of $\mathrm{C}=\mathrm{O}$. Raman spectra at the peak of wavenumber $1664 \mathrm{~cm}^{-1}$ also decrease intensity, representation of group vibration secondary $>\mathrm{NH}$.

The groups mentioned above are the groups responsible for the hydrogen bond in the crystal structure of LPV. The decrease in vibration intensity indicates the hydrogen bond in the lattice crystal structure has been broken. In the LPV compression process, the FTIR spectra at the peak of the $3400-3300 \mathrm{~cm}^{-1}$ wave number broaden after compression, and a new peak emerged at the peak wavenumber of $1703 \mathrm{~cm}^{-1}$ (Fig. 6). This result indicates a shift in lattice crystals after compression. The hydrogen bonds between molecules in the lattice crystal are closer to the $\mathrm{C}=\mathrm{O}$ group. Table 2 shows that the compression shifts the $2 \theta$ angle of the LPV to the right. The largest shift occurred in LPV compression in comparison with RTV and LPV/r. The $2 \theta$ angle right shift proves that the smaller $d$-spacing associated with the FTIR spectra, by the appearance of a strong vibrational peak at $1703 \mathrm{~cm}^{-1}$. This hypothesis is supported by the tabletability data that shows the tensile strength of LPV is greater than RTV (Fig. 7). A peak at $1659 \mathrm{~cm}^{-1}$ appears in the infrared spectrum of RTV under compression, but the intensity is not as high as LPV. Table 2 shows that the $2 \theta$ angle shift of the RTV is not as signifi- 
cant as LPV; only slight changes occur in the $d$ spacing or the lattice spacing of the RTV molecules. As a result, the tensile strength in RTV tabletability differs significantly from LPV. The grinding and compression of LPV/r change its local structure, reflected in its FTIR spectra by the peak intensity decrease and the appearance of new peaks derived from the properties of LPV $\left(1703 \mathrm{~cm}^{-1}\right)$. Therefore, the extent of the $2 \theta$ angle shift seen in XRD is strongly influenced by the LPV properties. Proven properties of LPV/r tabletability are almost equal to those of LPV.

\section{Tabletability}

LPV and RTV tablets were made at applied pressures of 37.5-265.5 MPa under controlled settings, and the tablet height, diameter, and hardness were evaluated. The tensile strength of the tablets was calculated using the well-known equation. The crystal structures of these systems were visualized, and slip planes were recognized. Tabletability is the capability of a powder to be converted into a tablet of definite strength under compaction pressure. The tabletability of a substance can be represented by a plot of tensile strength versus compaction pressure. A good tabletability means it is easier to make the preparation of drugs in tablet form $(37,38)$. Figure 7 shows that the tabletability of LPV is better than RTV. The combination of LPV/r increases the tabletability characteristic of RTV. Good tablets have high tensile strength with low compression pressure. Figure 7 showed that the LPV tensile strength increases sharply when the compression pressure is $75 \mathrm{MPa}$, but at high-level compression pressure, the tensile strength decreased. The degree and strength of inter-particulate bonding, a consequence of the particle reordering and deformation, controls the tablet construction and its mechanical strength. The plastic materials are susceptible to form a larger inter-particulate bonding area under compaction that results in tablets with good mechanical strength. An in-depth analysis of the crystal structures of LPV and RTV is presented in the next paragraphs, providing important insights into the reasons for these differences.

Figures $8 \mathrm{a}$ and $8 \mathrm{c}$ show an LPV and RTV diffractogram with hkl notation, respectively. Figures. $8 \mathrm{~b}$ and $8 \mathrm{~d}$ are a simulation of LPV and RTV structure inside the crystal lattice, respectively. There were eight molecules of LPV and four molecules of RTV in a crystal unit. The simulated image of this single crystal structure was created by the Mercury 3.7 software. LPV and RTV have the same functional groups related to the hydrogen bonding on their crystal structure. LPV and RTV both had the same space group $\left(\mathrm{P} 2_{1} 2_{1} 2_{1}\right)$, orthorhombic crystal system and potential slip planes, but the $d$-spacing of LPV is larger than that of RTV (12). In Figure 8b, the plane of LPV hkl on the $2 \theta$ angle diffractogram, there was (002), (020), and (111). At the hkl (002)
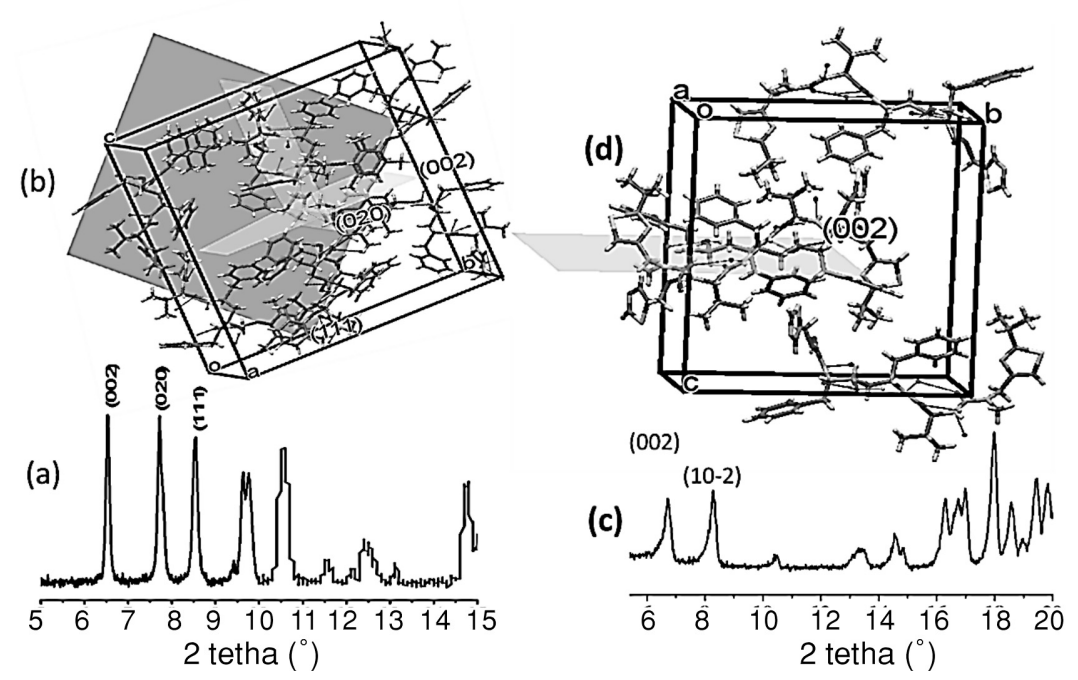

Figure 8. Views (a) and (c) show powder X-ray diffraction patterns of LPV and RTV, respectively. Views (b) shows a potential slip plane in the LPV crystal planes representing crystal lattices hkl (111), (002), (020). View (d) shows an RTV crystal with the plane representing crystal lattice hkl (002), deduced from the intermolecular interactions along the planes on the largest $d$-spacing. 


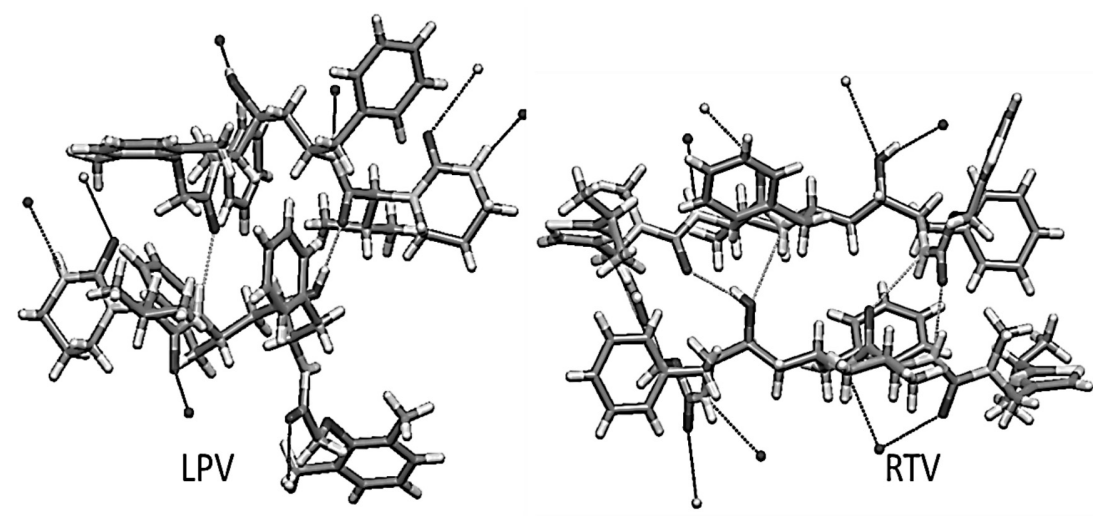

\begin{tabular}{|c|c|c|c|c|}
\hline No & Group & Assignment & \multicolumn{2}{|c|}{ Frequency $\left(\mathrm{cm}^{-1}\right)$} \\
\cline { 4 - 5 } & & & LPV & RTV \\
\hline 1 & $-\mathrm{OH} \ldots . \mathrm{O}=\mathrm{C}<$ & $\mathrm{OH}$ str. & 3370 & 3327 \\
\hline & & $\mathrm{C}=\mathrm{O}$ str. & 1703 & \\
\hline 2 & $>\mathrm{NH} \ldots . \mathrm{O}=\mathrm{C}<$ & $\mathrm{NH}$ str. & 3275 & 3357 \\
\hline & & $\mathrm{C}=\mathrm{O}$ str. & 1659 & 1659 \\
\hline 3 & $>\mathrm{NH} \ldots . . . \mathrm{HO}-$ & $\mathrm{NH}$ str. & 3275 & \\
\hline & & $\mathrm{OH}$ str. & 1647 & 1604 \\
\hline
\end{tabular}

Figure 9. Molecular vibration assignments involving hydrogen bonding in LPV and RTV solids.

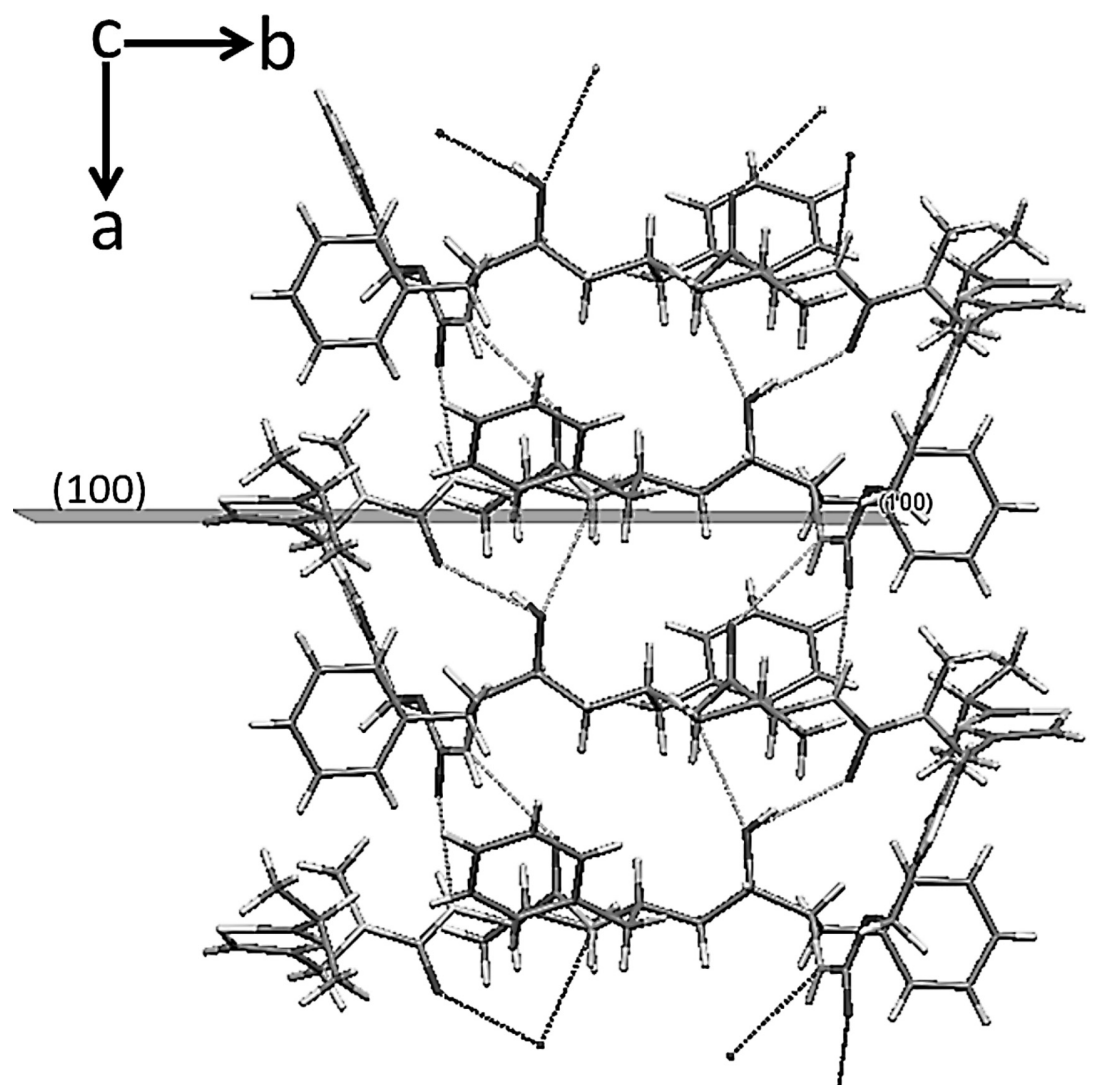

Figure 10. RTV crystal packing exhibits the intermolecular hydrogen bonds with respect to the (100) hkl plane that is presented by the thick line. 
plane, there was no hydrogen bond between the interplanar LPV molecules, only solvate or hydrate, in contrast to the plane (020) and (111) where there were two hydrogen bonds. Plane (002) was very potent as a slip plane for LPV under pressure. This plane slips more easily than both other planes because there was no hydrogen bonding. The plastic deformation was influenced by the slip plane in the interaction of interplanar materials. Weak interplanar interaction would provide the most likely place for a slip plane $(39,40)$. Proven compression pressure affected the $2 \theta$ angle shift to the right in the diffractogram XRD and increasing intensity at the peak of wavenumber 3400-3300, 1600-1800 cm-1 vibration in FTIR and $1500-1700 \mathrm{~cm}^{-1}$ vibration in Raman. Thus, the distance between the hydrogen bonds of LPV in the crystal lattice became closer, so the (020) and (111) hkl planes could not be slip planes. The $d$-spacing of the crystal lattice was affected by compression pressure and changes to be more closely spaced so that the hydrogen bonds of the interplanar functional groups became stronger. The spacing is also verified by the FTIR vibration spectrum at the peak of wavenumber $1659 \mathrm{~cm}^{-1}$ which represents one of the interplanar hydrogen bonds of functional groups $\mathrm{C}=\mathrm{O}$ or $\mathrm{OH}$ (Fig. 9). Previously, that peak of wavenumber $1659 \mathrm{~cm}^{-1}$ was not present before compression.

Unfortunately, RTV slip planes are more complicated than LPV. The potential the RTV slip planes did not have an inhibited look like the LPV, but in the (002), (111), (020) plane, there were many hydrogen and covalent bonds in the crystal lattice. The (100) hkl plane of RTV shows more potential for being a slip plane than hkl (002) and (111) (Fig. 10). In this plane, six hydrogen bonds connected to the functional group of the RTV molecule in the cell unit. However, the FTIR and Raman vibrations of each of these functional groups still appeared when compressed. This evidence showed that it was very difficult to slip on the (100) hkl plane because each hydrogen bond among the functional groups still existed, and it means that RTV did not have a slip plane as good as LPV for plastic deformation under compression. Therefore, the tensile strength of RTV did not lead to the same good tableting performance as LPV.

\section{CONCLUSION}

PXRD diffraction provides an excellent explanation for analyzing the phase transformation and solid-state interaction of LPV and RTV due to grinding and compression processes. This phenomenon was further clarified by the dynamics of the endothermic peak shift of the DSC thermogram. Based on the SCXRD analysis and supported by FTIR and Raman spectroscopy, the hkl (002) crystal lattice of LPV was predicted to have a slip plane that causes the plastic deformation during the compression process.

\section{Acknowledgments}

The authors acknowledge the Ministry of Research, Technology and Higher Education (Menristekdikti) of Indonesia and LPP UAD for supporting this research financially.

\section{Conflict of interests}

The authors declare no conflict of interest.

\section{REFERENCES}

1. Lin I.J., Nadiv S.: Mater. Sci. Eng. 39, 193 (1979).

2. Khomane K.S., More P.K., Raghavendra G., Bansal A.K.: Mol. Pharm. 10, 631 (2013).

3. Ainurofiq A., Mauludin R., Mudhakir D., Soewandhi S.N.: Marmara Pharm. J. 22, 570 (2018).

4. Blagden N., de Matas M., Gavan P.T., York P.: Adv. Drug Deliv. Rev. 59, 617 (2007).

5. Pandey A., Rath B., Dwivedi A.K.: Int. Curr. Pharm. J., 2, 70 (2013).

6. Patel S., Kaushal A.M., Bansal A.K.: Crit. Rev. Ther. Drug Carr. Syst. 23, (2006).

7. Lin S.-Y.: Asian J. Pharm. Sci. 2, 211 (2007).

8. Erizal, Yeyet Cahyati S., Sundani Nurono S., Halim A.: Int. J. Pharmacol. 4, 140 (2008).

9. Vadher A.H., Parikh J.R., Parikh R.H., Solanki A.B.: AAPS PharmSciTech. 10, 606 (2009).

10. Mohan S.: IJPSR 3, 1580 (2012).

11. Zimper U., Aaltonen J., McGoverin C.M., Gordon K.C., Krauel-Goellner K., Rades T.: Pharmaceutics 2, 30 (2010).

12. Bandyopadhyay R., Selbo J., Amidon G.E., Hawley M.: J. Pharm. Sci. 94, 2520 (2005).

13. Ainurofiq A., Mauludin R., Mudhakir D., Setianto A.B., Soewandhi S.N.: Key Eng. Mater. 787, 43 (2018).

14. Mishima O., Calvert L.D., Whalley E.: Nature 314, 76 (1985).

15. Thakral N.K., Mohapatra S., Stephenson G.A., Suryanarayanan R.: Mol. Pharm. 12, 253 (2015).

16. Goyal G., Vavia P.R.: J. Incl. Phenom. Macrocycl. Chem. 73, 75 (2012). 
17. Lemmer H.J.R., Liebenberg W.: Pharmazie 68, 327 (2013).

18. Madan S., Madan S.: Asian J. Pharm. Sci. 7, 123 (2012).

19. Rosenberg J., Reinhold U., Liepold B., Berndl G., Breitenbach J., et al.: Solid Pharmaceutical Dosage Formulation. US8377952 B2. (2013).

20. Fule R., Amin P.: Biomed Res. Int. 146781 (2014).

21. Ainurofiq A., Mauludin R., Mudhakir D., Soewandhi S.N.: Pharmaceutics 10, 85 (2018).

22. Sun C.C.: J. Pharm. Sci. 98, 1 (2009).

23. Roberts R.J., Rowe R.C., York P.: Int. J. Pharm. 125, 157 (1995).

24. Khomane K.S., More P.K., Bansal A.K.: J. Pharm. Sci. 101, 2408 (2012).

25. Hussain F., Hayat S.S., Shah Z.A., Ahmad S.A.: Chin. J. Phys. 51, 347 (2013).

26. Davis T.D., Morris K.R., Huang H., Peck G.E., Stowell J.G., et al.: Pharm. Res. 20, 1851 (2003).

27. Davis T.D., Peck G.E., Stowell J.G., Morris K.R., Byrn S.R.: Pharm. Res. 21, 860 (2004).

28. Rasanen E., Rantanen J., Jorgensen A., Karjalainen M., Paakkari T., Yliruusi J.: J. Pharm. Sci. 90, 389 (2001).
29. Hu Y., Liang J.K., Myerson A.S., Taylor L.S.: Ind. Eng. Chem. Res. 44, 1233 (2005).

30. Bauer J., Spanton S., Henry R., Quick J., Dziki W., et al.: Pharm. Res. 18, 859 (2001).

31. Park S., Baker J.O., Himmel M.E., Parilla P.A., Johnson D.K.: Biotechnol. Biofuels 3, 10 (2010).

32. Jacob S., Nair A.B., Patil P.N., Panda B.P.: Int. J. Pharm. Sci. Res. 2, 472 (2011).

33. Pirttimaki J., Laine E., Ketolainen J., Paronen P.: Int. J. Pharm. 95, 93 (1993).

34. Kiss A.A., Suszwalak D.J.P.C.: Sep. Purif. Technol. 86, 70 (2011).

35. Nigmatullin R., Baleanu D., Al Zaydi K., Alhamed Y., H Zahid A., Youssef T.: Rev. Chim.-Bucharest 64, 987 (2013).

36. Monshi A, Foroughi M.R., Monshi M.R.: World J. Nano Sci. Eng. 2, 154 (2012).

37. Bag P.P., Chen M., Sun C.C., Reddy C.M.: CrystEngComm. 14, 3865 (2012).

38. Ahmed H., Shimpi M.R., Velaga S.P.: Drug Dev. Ind. Pharm. 43, 89 (2017).

39. Feng Y., Grant D.J.W., Sun C.C.: J. Pharm. Sci. 96, 3324 (2007).

40. Sun C.C.: Sci. Technol. 25, 483 (2012).

(C) 2020 by Polish Pharmaceutical Society. This is an open-access article under the CC BY NC license (c) (i) () (http://creativecommons.org/licenses/by-nc/4.0/). 